\section{EMBRYRIDDLE}

Aeronautical University

SCHOLARLY COMMONS
Journal of Aviation/Aerospace Education \& Research

Volume 13

Number 1 JAAER Fall 2003

Article 9

Fall 2003

\title{
VFR Flight Into IMC: Reducing the Hazard
}

Dale R. Wilson

Teresa A. Sloan

Follow this and additional works at: https://commons.erau.edu/jaaer

\section{Scholarly Commons Citation}

Wilson, D. R., \& Sloan, T. A. (2003). VFR Flight Into IMC: Reducing the Hazard. Journal of Aviation/ Aerospace Education \& Research, 13(1). https://doi.org/10.15394/jaaer.2003.1567

This Article is brought to you for free and open access by the Journals at Scholarly Commons. It has been accepted for inclusion in Journal of Aviation/Aerospace Education \& Research by an authorized administrator of Scholarly Commons. For more information, please contact commons@erau.edu. 
Wilson and Sloan: VFR Flight Into IMC: Reducing the H azard

VFR Flight Into IMC

\title{
VFR FLIGHT INTO IMC: REDUCING THE HAZARD
}

\author{
Dale R. Wilson and Teresa A. Sloan
}

\begin{abstract}
Aircraft accidents resulting from initiating or continuing visual flight rules (VFR) flight into instrument meteorological conditions (IMC) continue to be one of the leading causes of fatal aircraft accidents. This paper outlines the nature and scope of this hazard and reviews past and present initiatives designed to reduce it. It also suggests future interventions that may be effective in reducing the threat of this aviation hazard.
\end{abstract}

\section{INTRODUCTION}

Aircraft accidents resulting from initiating or continuing visual flight rules (VFR) flight into instrument meteorological conditions (IMC) is one of the leading causes of fatal aircraft accidents. When VFR-into-IMC accident pilots inadvertently enter cloud, they either fly under controlled flight into terrain (CFTT) or experience spatial disorientation and lose control of the aircraft resulting in an unrecoverable unusual flight attitude (e.g., spin or graveyard spiral) or inflight structural failure. Studies conducted at the University of Illinois indicate that for the pilot who does not have adequate instrument flight training, the average time from cloud entry to loss of control or ground impact is 178 seconds ("178 seconds," n.d.). Unfortunately, the accident record indicates that VFR flight into IMC continues to be a significant threat to aviation safety. This paper outlines the nature and scope of the hazard, reviews past and present initiatives designed to reduce it, and suggests future interventions which may be effective in reducing this aviation hazard. VFR-into-IMC Accident Record

The U.S. National Transportation Safety Board (NTSB) found that during the twelve years through 1975 to 1986, even though VFR flight into IMC accounted for only $4 \%$ of U.S. general aviation (GA) accidents, it was responsible for $16.7 \%$ and $19 \%$ of fatal GA accidents and fatalities respectively (NTSB, 1989). For a similar time period in Canada (1976 to 1985), the Transportation Safety Board of Canada (TSBC) found that continued VFR flight into IMC accounted for only $6 \%$ of all aviation accidents yet was responsible for $23 \%$ of fatal accidents and $26 \%$ of fatalities, making it the leading single cause of aviation fatalities in that country (TSBC, 1990a). During this period, a combined total of approximately 1770 VFR-into-IMC accidents occurred in both countries, averaging one accident and 1.5 fatalities every two days (NTSB, 1989; TSBC, 1990a). Similar findings are reported for the United Kingdom (UK) where continued flight into adverse weather was responsible for an average of $24 \%$ of all single-engine aircraft accidents for the 15 years between 1980 and 1994, and one-third of all fatal GA accidents in 1994 alone (Leannount, 1995).

These data indicate that even though the incidence of VFR-into-IMC accidents is quite low, they are responsible for a disproportionately high percentage of fatal accidents and fatalities. For example, the NTSB study (1989) found $17.3 \%$ of all GA accidents resulted in fatalities, yet a full $72.2 \%$ of VFR-into-IMC accidents were fatal. A recent Aircraft Owners and Pilots Association (AOPA) Air Safety Foundation (1996) study of VFR-into-IMC accidents, which occurred between 1982 and 1993, found an even higher percentage (82\%) of these accidents involved fatalities.

Even though the percentage of U.S. GA VFR-into-IMC accidents dropped from 4\% in 1982 to 3\% by 1993-which reflects the overall decline in weather-related accidents from $31 \%$ in 1982 to $20 \%$ in 1993 (AOPA, 1996) there is evidence that it may have leveled off. A recent weather safety study conducted by the Federal Aviation Administration (FAA) found the percentage of weather-related accidents to total accidents remains stable at 23\% since 1995 (FAA, n.d.). Since approximately $70 \%$ 
of fetal GA weather-related accidents result from attempted VFR flight into IMC (AOPA, 1999, 2001), it is likely that this leveling off in the proportion of weather-related accidents reflects an overall leveling off of the VFR-into-IMC accident rate as well. Regardless, recent data make it clear that VFR flight into IMC is still the leading cause of fetal $\mathrm{G} \mathrm{A}$ weather-related accidents and continues to be one of the most frequent causes of all fatal GA accidents (AOPA 19\%, 2001). Type of Flight Operations

Many VFR-into-IMC accidents involve G A aircraft used primarily for personal purposes and piloted mostly by relatively low-time pilots. For example, of the 361 VFR-into-IMC accidents in the United States between 1983 and early $1987,62 \%$ of pilots were flying their own aircraft and $75 \%$ of the accident flights were for personal purposes (NTSB, 1989). Between 1989 and 1999, the FAA found that $71 \%$ of 14 CFR Part 91 aircraft involved in weather-related accidents were used for personal purposes (FAA, n.d). The AOPA Air Safety Foundation (1996) also reported that $58 \%$ of G A VFR-into-IMC accident pilots had fewer than one thousand hours of flight experience. However, only 5\% had fewer than one hundred hours, presumably because these pilots fly mostly under the supervision of a flight instructor in a relatively protected training environment.

However, these accidents are not solely restricted to low-time GA pilots-a surprisingly high proportion involve experienced pilots and those engaged in commercial flight operations. One-third of GA VFR-into-IMC accidents in the United States involved pilots with one thousand flight hours or more and one-quarter involved pilots with over two thousand hours. In Canada, almost $20 \%$ of the accident pilots had three thousand or more hours of flight experience (AOPA, 19\%; NTSB, 1989, TSBC, 1990a). Recent studies also indicate that a significant portion of CFTT accidents-the world's leading cause of commercial aviation fatalities (Menzel, 1998)-are the result of attempted VFR flight into IMC. Khatwa and Roelen (19\%) found that VFR flight into IMC was responsible for at least $19 \%$ of worldwide commercial CFTT accidents that occurred between 1988 and 1994. (The percentage is likely higher since data were missing in $43 \%$ of the sample accidents.) An even higher percentage is reported in Canada where over half of the seventy commercial CFTT accidents between 1984 and 1994 involved flight crews attempting visual flight in IMC (TSBC, 19\%). Commercial flight operations in Canada shared a significant proportion of that country's VFR-into-IMC accidents a full 35\% over a ten-year period (TSBC, 1990a). In the United States, Alaska has the worst record for VFR-into-IMC accidents, not only in the GA sector but for commercial flight operations as well (see Figure 1).

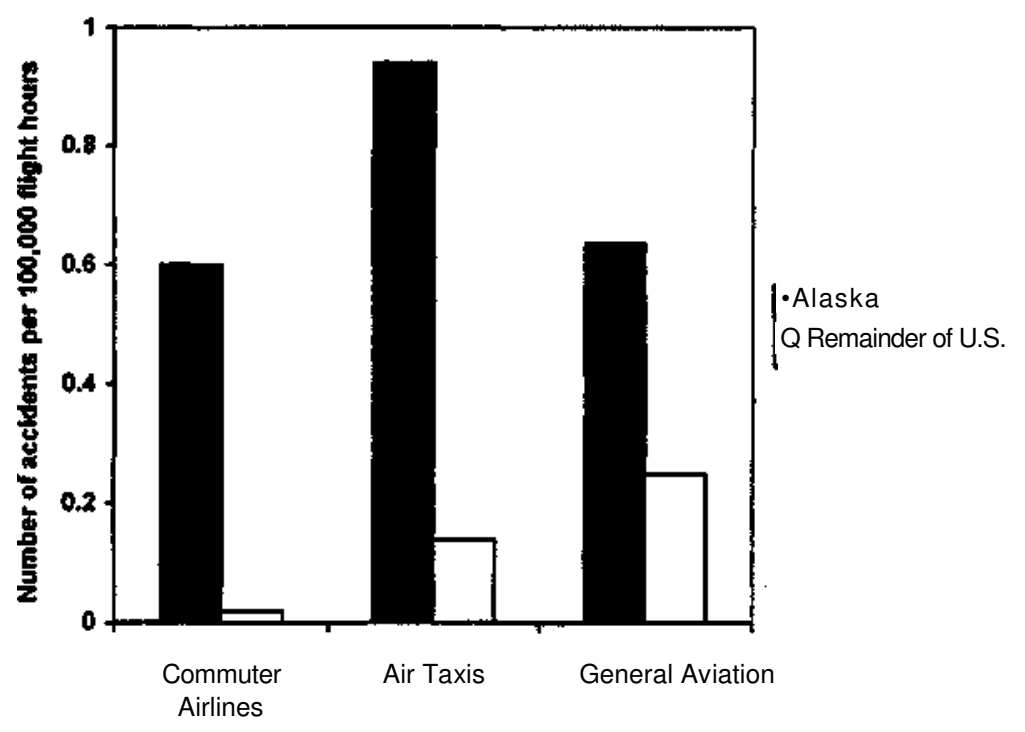

Figure 1. VFR-into-IMC accident rates for five-year period 1989 though 1993. Adapted from Safety study: Aviation safety in Alaska (NTSB/SS-95/03), (p. 24), 1995, Washington, DC: National Transportation Safety Board. 
For the five-year period between 1989 and 1993, these accidents were responsible for $47 \%$ and $67 \%$ of Alaska's fatal air taxi and commuter accidents respectively (NTSB, 1995). In fact, a recent study conducted by the U.S. National Institute for Occupational Safely and Health (NIOSH) found that aircraft accidents are the leading cause of occupational fatalities in Alaska, and that CFTT resulting from attempted flight into IMC is the number one cause of these accidents (Hall, 19\%; LaBelle, 1999).

\section{Adverse Weather}

A number of environmental factors increase the probability of VFR-into-IMC accidents. The first obvious factor is adverse weather in the form of cloud, precipitation, or fog. VFR flight dictates that minimum cloud clearance and visibility requirements be met, and for certain flight operations (e.g., 14 CFR Part 135 VFR helicopter operations in the United States) and countries (such as Canada) visual contact with the earth's surface must be maintained. Mountainous Terrain

Adding mountainous terrain to VFR flight in marginal weather substantially increases the risk. Over half of all VFR-into-IMC accidents for a ten-year period in Canada occurred in mountainous terrain (TSBC, 1990b). Also, $62 \%$ of foreign-registered VFR-into-IMC accidents in Canada occurred in the mountainous regions of British Columbia (BC) and the Yukon Territory (TSBC, 1990b). Over the most recent ten-year period for which data is available (1991-2000), British Columbia continued to have the highest number of fatal accidents-about $39 \%$ more than Ontario, the province with the highest number of total accidents (TSBC, 2001).

Of the ten U.S. states that had the highest percentage of VFR-into-IMC accidents between 1975 and 1986, eight are located in FAA-designated mountainous areas (NTSB, 1989). For fiscal years 1989-1993, the U.S. General Accounting Office (USGAO) found the GA accident rate for the eleven western continental states (all FAA-designated mountainous areas) averaged 2.4 accidents per 100,000 operations- $40 \%$ higher than the rate of 1.7 for the other thirty-seven continental states (USGAO, 1993). Also, the average rate for Hawaii and Alaska-both within designated mountainous areas-exceeded the 1.7 rate by $39 \%$ and $580 \%$ respectively (USGAO, 1993).

Mountain ranges located in western North America act as natural lifting agents for moist air moving inland from the Pacific Ocean. When the base of overcast cloud drops below the mountaintops, a giant labyrinth consisting of a limited number of narrow winding corridors results. For the pilot who attempts VFR flight under the cloud, a practice often referred to as scud running, the lack of remaining available options (i.e., VFR over-the-top, IFR clearance, reverse course) substantially increases the risk. Pilots can inadvertently fly into a dead-end valley where terrain rises faster than the aircraft can climb or get boxed into a narrow valley with little or no room to perform a 180-degree turn. Also, rapidly changing mountain weather can close in behind pilots leaving them no way out. Night

Another important environmental factor that increases the level of risk is the darkness of night. There is an increased chance of inadvertent entry into cloud or fog at night (AOPA, 1996; Wilson, 1999). A full third of all VFR-into-IMC accidents in the United States and 30\% of such accidents in Canada occur at night, even though the estimated GA VFR activity in both countries at night is only about 10\% (AOPA, 1996, NTSB, 1989; TSBC, 1990b). Also, the major cause of fatal commercial Emergency Medical Service (EMS) helicopter accidents over a nine-year period was VFR flight into IMC, with most occurring at night (NTSB, 1988). Even in good visual meteorological conditions (VMC) there is an increased accident risk for VFR flight at night (Wilson, 1999). How much more is the risk in adverse weather? As the following account illustrates, it can be very difficult to detect inclement weather at night.

I left XYZ later than I originally intended. In retrospect, I should not have left at a time that would require night VFR flight, given the cloud conditions.... I did not notice entering IMC at first, and, in fact, remember being curious why the anti-collision lights were illuminating the cockpit and causing a strobe effect on the prop. Shortly thereafter, I noticed that the turn coordinator was pegged in a left turn, the attitude indicator showed a $45-60^{\circ}$ left bank, the directional gyro was spinning rapidly. . . . I recognized the signs of [an impending] "graveyard spiral" and was able to return the plane to straight-and-level flight. The real cause [of this incident] was ... lack of appreciation of the danger of night VFR. ("Night for Day," 19\%, p. 1) A number of initiatives have been undertaken to reduce the VFR-into-IMC hazard. These have focused 
Journal of Aviation/A erospace Education \& Research, Vol. 13, No. 1 [2003], Art. 9

primarily on: 1.) regulatory reforms, 2.) improving the operational environment, 3.) developing advanced technology, and 4.) enhancing pilot training and education.

\section{VFR Weather Minima}

\section{REGULATORY REFORMS}

In both the United States and Canada, VFR-into-IMC accidents have occurred in meteorological conditions which met or exceeded the minimum regulatory requirements ("Night-visual flight rules," 1989; TSBC, 1990b, 19\%). These mininuuns have also been cited as a contributing factor in some of these accidents (TSBC, 19\%). Investigators, citing scientific data regarding the inherent limitations of human depth/distance perception and information processing ability, conclude that when pilots fly in the impoverished visual conditions of marginal VFR weather, it is virtually impossible not only to accurately judge one mile visibility from a moving aircraft, but to detect deteriorating conditions in time to avoid inadvertent flight into IMC (TSBC, 1996). Just as automobile drivers can overdrive their headlights when driving at night, precluding them from detecting objects in sufficient time to avoid a collision, so too is it easy for pilots to overfly their visibility when flying in conditions of reduced visibility. Exacerbating the problem is the phenomenon of aerial perspective, where distances from objects and terrain tend to be overestimated in conditions of reduced visibility (Ross, 1975). Also, in mountainous terrain maneuvering room is minimal when flying through narrow valleys under an overcast cloud deck. The increase in turning radius which occurs at the higher altitudes usually associated with mountain flying makes it difficult for pilots to safely execute a ISO-degree course reversal should one be required.

Regulatory agencies have recognized the inadequate margin of safety provided by traditional VFR. weather minima. For example, in 1989 the United States raised the minimum of one mile visibility (and clear of cloud) applicable to VFR flights in uncontrolled (class G) airspace at night, to the higher controlled airspace (class C, $\mathrm{D} \& \mathrm{E}$ ) minimum of three miles visibility (with minimum horizontal/vertical cloud clearance distances) ("Night-visual flight rules," 1989). Canada followed suit in $19 \%$ by raising the one-mile visibility requirement to three miles in uncontrolled airspace at night (Transport Canada, 1996a). For special VFR operations at night, both the United States (under Title 14, Code of Federal Regulations [14 CFR]) and
UK require pilots and their aircraft to be certified for instrument flight, and Canada now only authorizes it for the purpose of getting the aircraft safely on the ground (14 CFR 91.157(b), 2000; Transport Canada, 1996b). In response to the dramatic increase in air tour accidents in the state of Hawaii, the FAA also published Special Federal Aviation Regulation (SFAR) Number 71-1, which effectively increases the weather minima by requiring VFR flights to operate above 1500 feet AGL ("Air tour operators," 1994). However, even though commercial VFR Part 135 air carriers require two miles visibility and recreational pilots are restricted to three, the basic visibility in uncontrolled airspace for day VFR operations in the United States still remains at one statute mile (14 CFR 135.205(a), 1991; 14 CFR 91.155(a), 1993; 14 CFR 61.101(d), 1997).

Recognizing the increased risk for VFR flight operations in mountainous terrain and in response to TSBC recommendation A90-67 (1990a), Canada raised the minimum visibility requirement to two miles in designated mountainous regions, then subsequently expanded the rule to apply to all uncontrolled airspace below 1,000 feet AGL during daylight hours (Transport Canada, 1996a; TSBC, $19 \%)$. Other countries have higher visibility requirements for day VFR flight in uncontrolled airspace. For example, Australia, New Zealand, and the UK require a minimum of three statute miles visibility (Civil Aviation Authority of New Zealand, 2002; Civil Aviation Safety Authority of Australia, 2002; United Kingdom Civil Aviation Authority, 19\%). The FAA may wish to consider the safety benefits of increasing the minimum visibility requirement for day VFR operations, if not for all low-level uncontrolled airspace, then at least for designated mountainous regions. Single-engine Commercial IFR Flight

A regulatory change that should lead to fewer fatalities involves allowing commercial passenger-carrying flights to operate under instrument flight rules (IFR) in single-engine aircraft. Canada has allowed single-engine IFR (SEIFR) passenger-carrying flights in turbine-powered aircraft since 1993 ("Commercial passenger-carrying," 1997; Transport Canada, 1996c). The United States followed suit in 1998 by allowing commercial SEIFR passenger-carrying operations in both turbine and reciprocating engine aircraft, provided minimum equipment and maintenance requirements are met ("Commercial passenger-carrying," 1997). Noting that VFR flight into IMC was the most significant cause of fatal 
commercial EMS helicopter accidents (NTSB, 1988) and 14 CFR Part 135 operator accidents in Alaska (NTSB, 1995), as well as a serious problem nation-wide, the FAA reasoned this hazard far outweighed the risks associated with an engine failure in IMC ("Commercial passenger-carrying," 1997). The option to conduct an BFR flight provides the benefits of the IFR system (i.e., safe obstacle clearance altitudes, ATC position following and assistance, availability of en route weather information, etc.) as well as a higher altitude from which to glide in the unlikely event of an engine failure-benefits which would otherwise be unavailable to the pilot when flying VFR at low altitudes below the clouds.

\section{OPERATIONAL ENVIRONMENT}

\section{Aviation Weather Services}

In order to make safe preflight and inflight decisions regarding the suitability of weather for VFR flight, pilots need accurate, comprehensive, and up-to-the-minute weather information specific to their route of flight. Unfortunately, this information has not always been available. In the United States, for example, the FAA is strongly criticized for not providing the leadership necessary to ensure the delivery of adequate weather information to pilots, controllers, and other users of the aviation system. Since 1995, at least four major reports have been critical of the lack of coordination between the FAA and the National Weather Service (NWS) which has resulted in a "fragmented" aviation weather system that at times is "unable to respond fully to the valid needs of pilots and other users" (National Research Council [NRC], 1995, p. 3; FAA Research, 1997; USGAO, 1998).

Since the consolidation of 317 Flight Service Stations (FSSs) in 1981 to the 61 Automated FSSs (AFSS) and 31 part-time and/or seasonal FSSs by the mid-1990s, many question the FAA's commitment to providing an equal or better level of service to users (NRC, 1995). The replacement of FAA and NWS weather briefers, who possess expert knowledge of local weather conditions, with an expanding automated surface observation system (ASOS) is also viewed by many aviation users as a degradation of service (NRC, 1995; USGAO, 1998). For example, ceiling and visibility values-both of which are critical elements to VFR pilots - are measured differently by ASOS and under certain conditions (e.g., rapidly changing weather) are inaccurate. ASOS measures ceiling over a narrow area directly overhead rather than over the entire celestial dome, and visibility is determined by the opacity of air between a transmitter and receiver located less than three feet apart (NRC, 1995).

The NRC (1995) recommended the FAA take action to address three identified aviation user needs: improved weather observations and forecasts; the distribution of graphic weather products "that allow pilots, controllers, and dispatchers to develop and maintain a consistent view of current and forecast weather conditions" (p. 39); and better weather training for pilots, controllers, and FSS personnel. Even though a USGAO report rated their progress as "very poor" (USGAO, 1998, p. 18), the FAA, through its Safer Skies and Safe Flight 21 initiatives, is addressing these weaknesses (FAA GA Joint Steering Committee, 2001; FAA Office of Safe Flight 21,2002) Air Traffic Control

VFR pilots may be reluctant to declare an emergency and request ATC assistance to escape the possibility of a CFIT accident resulting from scud running below the clouds or to get themselves safely down from above a solid overcast sky condition. It is not known to what extent the threat of disciplinary action has precluded pilots who were legitimately in trouble from requesting assistance. Most certainly, if a pilot requests priority assistance from ATC in the United States, the local FAA Flight Standards District Office (FSDO) will be notified and they in turn are obliged to conduct an investigation. However, pilots need to realize that the FAA is well aware that some pilots may be more afraid of confessing their need for help than they are of the actual condition itself. Therefore, to encourage pilots to take whatever steps necessary to achieve a safe outcome for a flight, including requesting a flight assist from ATC in an emergency (or urgency) situation, they rarely take enforcement action unless absolutely necessary (BertoreUi, n.d.; FAA, 2000). They prefer to talk with pilots (by telephone or in person) to help them avoid such situations in the future. Only if it is clearly a case of willful careless or reckless operation of the aircraft, or the person is a repeat offender, will they issue a warning or take enforcement action (BertoreUi, n.d.; FAA, 2000).

\section{Weather Data Delivery}

\section{TECHNOLOGY}

New advancements in cockpit technology have the potential to provide significant safety benefits to GA pilots. One of the goals of the FAA's Safer Skies and Safeflight 21 programs (initiated in 1998 and 2000 respectively) is to increase the availability of accurate inflight weather data through technology which is "affordable by a significant 
portion of the GA fleet by 2007" (FAA GA Joint Steering Committee, 2001, para. 3). The FAA's Flight Information Service Data Link (FISDL), which provides nationwide VHP frequencies for transmission of real-time weather data, became operational in August 2000. The two FAA-contracted service providers-ARNAV Systems and Honeywell International-provide the ground infrastructure for the data link. Aircraft equipped with the appropriate receiver and multi-function display (MFD) can receive textual weather products (METARs, TAFs, etc.) at no charge and graphic information, such as NEXRAD radar images, for a nominal fee (Goyer, 2000). The cost to the consumer for receiver/MFD systems range from about $\$ 8,000$ to $\$ 13,500$ (ARNAV Systems, 2001; Bendix/King, n.d.)-certainly lower than comparable systems installed in commercial air carrier aircraft, yet still likely not affordable for many GA aircraft owners.

Alaska and Canada have experimented, to a limited degree, with providing video camera images of real-time weather conditions in remote mountainous areas to VFR pilots. Expanding such coverage, especially in mountainous regions, would provide VFR pilots with valuable real-time weather information that might otherwise be unavailable. In the United States it is conceivable that such images could be delivered to VFR pilots through the FISDL system, thus enhancing their decision making ability.

\section{Terrain Awareness}

Global Positioning System (GPS) and advancements in computer-chip technology have contributed to the proliferation of terrain awareness technology for GA aircraft. This technology can be used as an aid to increase the situational awareness of pilots who may find themselves flying in marginal visual conditions. Most units display terrain information derived from GPS position information synchronized with a worldwide terrain elevation database. For example, the Echo Flight system uses Landsat terrain imagery to provide a color display that can actually help a pilot to distinguish open areas from areas with buildings or trees even in IMC or at night (Echo Flight, 2002). UPS Aviation Technologies, Honeywell's Bendix/King, and other manufacturers offer comparable systems, with some providing visual and aural warning of terrain through an Early Ground Proximity Warning System (EGPWS) (Nordwall, 2000). The price for this technology ranges from as low as \$6,000 to about \$15,000 (Echo Flight, 2002; UPS Aviation Technologies, 2002).

\section{Synthetic Vision}

Technology that ultimately holds out the most promise for VFR pilots is synthetic vision (S V). Using GPS position information and an accurate terrain database, SV provides the pilot with a high fidelity virtual-reality display of the outside world. A variety of systems are currently being developed. Some present information in a three-dimensional moving display while others will provide an out-the-window view with highway in the sky (HITS) overlays (Braukus \& Barnstorff, 1999; Sakrison, 2001). Theoretically such technology (and its costs) could evolve to the point where the typical VFR pilot could look directly out the window in IMC and/or at night and view an accurate, realistic, and reliable computer-generated visual scene of the outside workL Although these first generation systems are designed to attract the general aviation market, costs are likely to initially be high for the typical GA aircraft owner.

\section{PILOT TRAINING}

\section{Instrument Rating}

In 1985, even though $46 \%$ of U.S. pilot certificate holders possessed an instrument rating, only $23 \%$ of the VFR-into-MC accidents between 1975 and 1986, and 27\% between 1982 and 1993, involved pilots with instrument ratings (AOPA, 1996; NTSB, 1989; TSBC, 1990a). Also, between 1976 and 1985, U.S. commercial pilots, 83\% of whom were instrument-rated in 1985, were proportionally involved in significantly fewer VFR-into-IMC accidents than their counterparts in Canada, where only $15 \%$ were instrument-rated (TSBC, 1990a). In 1997, the FAA eliminated the 125-hour total time requirement under 14 CFR Part 61.61 ("Pilot, Flight Instructor," 1997). According to Scott Gardiner (personal communication, April 26, 2002), Safety Program Manager at the Seattle FSDO, low time pilots who meet the practical test standards for an instrument rating, and who obtain and use that rating, are less likely to scud run. VFR pilots should recognize the increased safety benefits of instrument training and possession of an instrument rating, and the aviation educational community should do all in its power to promote and facilitate such training. Risk Awareness Training

In an effort to attract customers and to extol the aviation safety record to the public, the aviation industry has unwittingly been responsible for promulgating what John King calls the Big Lie regarding GA safety (Wallace, 2001). This is most often illustrated in the statement; The 
most dangerous part of the flight is the drive to the airport." The fact is, even though the GA accident rate per mile is about one-tenth that of the motor vehicle rate, the fatal accident rate is about seven times higher (AOPA, 1999). Rather than shy away from discussions about risk, flight instructors and aviation educators should be educating students about the varying degrees of risk inherent in specific flight operations. Informing pilots of the probabilities, consequences, and situations in which VFR-into-IMC accidents are likely is a necessary first step in teaching them how to reduce the risks associated with VFR flight in marginal weather conditions. Hazardous Weather Awareness Training

To avoid hazardous weather, VFR pilots must be able to recognize it, both through personal observation and the proper interpretation of aviation weather forecasts and reports. Not only does this require a significant level of understanding of meteorological processes and weather hazards to flight, but also the ability to generate adequate predictions of future weather based on personal observations and aviation weather reports. The training necessary to achieve this certainly goes far beyond the minimum Private Pilot ground school requirements specified by most regulatory agencies. Collegiate aviation programs are ideally suited to provide this type of training. College-level aviation weather courses not only provide an opportunity for a deeper understanding of meteorology and the weather hazards peculiar to the flight environment, but also the practical application of this knowledge through simulated cross-country exercises integrated with weather service products designed to help students determine the suitability of weather for VFR flight.

The FAA Private Pilot Airmen Knowledge Test, designed to test the level of an applicant's knowledge, is considerably weak in this area. It wasn't until 1999 that questions (only two) dealing with continued VFR flight into adverse weather were finally introduced. However, the databank continues to be heavily biased toward convective and turbulence hazards and includes only one question on low-pressure systems (altimeter errors). None specifically identify warm frontal weather-both of which are associated with extensive areas of low ceilings and visibilities common to many VFR-into-IMC accidents (FAA, 2002). A significant increase in the number of questions which seek to apply weather theory to practical situations, such as integrating weather report and forecast questions with a sample cross-country trip (as is done in Private Pilot knowledge tests in Canada), would also contribute to the elevation of weather competency among newly certified pilots.

\section{Weather-Related Decision Making Training}

The fact remains that either actively or by default, pilots involved in these accidents made the decision to initiate or continue VFR flight into adverse weather. Human decision making has received considerable attention by researchers over the past three decades, with a subdiscipline developed and devoted strictly to aviation known as aeronautical decision making (ADM). Unfortunately, research has yielded few definitive findings about this most complex of human thought processes. What little has been discovered has also taken considerable time to make its way into pilot training programs.

There is a substantial body of research that indicates normal human decision making is often not very rational and is subject to bias. For example, Wichman and Ball (1983) and CVHare (1990) found that most GA pilots are unrealistically optimistic regarding their chances of experiencing an aircraft accident, and believe they possess greater flying skill and are less likely to experience an aircraft accident or take risks in flight, than their peers. Wilson and Fallshore (2001) discovered these optimistic and ability biases also extend to the VFR-into-IMC scenario. They found that most VFR pilots are overly optimistic regarding their chances of experiencing a VFR-into-IMC accident, and are also overconfident in their ability to both avoid and successfully fly out of IMC.

When evaluating all 14 CFRPart 91 aircraft accidents between 1990 and 1997, Gob and Wiegmann (2001) also found a significantly greater percentage of VFR-into-IMC accident flights carried passengers on board. In Alaska, $50 \%$ of commercial pilots and operators surveyed flew under VFR into IMC at least once in response to operational pressures (NTSB, 1995). The role of social pressure, along with how other decision biases may contribute to what has historically been called get-there-itis, is currently being examined by researchers and will hopefully shed more light on why VFR pilots continue to press on into deteriorating weather conditions.

Aviation educators and flight instructors play a key role in teaching their students how to avoid a VFR-into-IMC situation. One way is to simulate hazardous weather recognition and weather-related decision making through pencil and paper exercises, computer-based training (CBT), and one-on-one or group discussions. The FAA, AOPA, 
and other organizations are beginning to provide training aids to help pilots in this area. The FAA sponsors an experimental web site (http://flysafe.faa.gov) which, through its Pilot Mastery Series, provides CD ROM and on-line CBT programs designed to help VFR pilots visually recognize the signs of deteriorating weather, determine how to make decisions in such weather, and set personal weather minimums for flight. It is hoped the development of such programs will continue and eventually be incorporated into the mainstream of pilot education programs delivered by industry and the FAA.

Finally, modeling a healthy respect for marginal weather and legal VFR weather minima teaches students by example how to avoid adverse weather. However, since it is likely that pilots will encounter such weather once they leave the relatively safe confines of the flight-training environment, there may be value in providing some actual marginal-VFR weather training to pilots. Deliberately exposing them to close-to-VFR-minimums could help them both recognize adverse weather conditions and learn the skills required to avoid inadvertent flight into IMC. The dangers of scud running below clouds, especially at night or in mountainous terrain, might also be more effectively emphasized. However, there is the danger of setting a poor example and possibly elevating the future risk-taking behavior of these trainees. Therefore, it should be made clear to them that this is specialized hazardous weather avoidance training, and regular flight training in such weather conditions should not take place.

\section{CONCLUSION}

VFR flight into IMC remains the leading cause of fatal $\mathrm{G} A$ weather-related accidents and continues to be one of the most frequent causes of all fatal GA accidents. Even though much has been done to reduce the frequency of these accidents, continued regulatory reforms and improvements in the operational environment, technology, and pilot training will further reduce the threat of this hazard. In that spirit, the following recommendations are made: Recommendations to $F A A$

1. The FAA should consider following the example of other countries by increasing the minimum daytime VFR visibility requirement to at least 2 miles in uncontrolled (Class G) airspace below 1200 feet AGL.

2. The FAA should continue its efforts to improve the quality of weather delivery to pilots including facilitating the development of technology that provides real-time in- cockpit weather information, especially in remote mountainous areas.

3. The FAA should increase the number of TV weather cameras in remote mountainous regions and make these images available to pilots via the Internet.

4. The FAA should increase the number of Private Pilot Airman Knowledge test questions that specifically deal with continued VFR flight into deteriorating weather conditions and the adverse weather associated with warm frontal and low pressure systems. Questions that integrate specific weather report and forecast elements that are applicable to a sample cross-country trip would also elevate the level of knowledge required of test applicants.

5. The FAA should continue its efforts regarding on-line training aids such as tiieflysafe.faa.gov experimental web site.

\section{Recommendations to Industry}

1. Part 135 VFR operators should consider taking advantage of the 1998 changes to 14 CFR Part 135 that allow operators, with certain stipulations, to fly SEIFR, thereby providing an extra margin of safety.

2. The aerospace industry and the FAA should continue to cooperate in the development of affordable cockpit technology and weather data delivery systems that will significantly increase safety for the low-end of the GA market. Recommendations for Training

1. VFR Pilots should be taught how to determine their own personal weather minimums for flight and the importance of adhering to them when faced with the pressure to fly below them.

2. Pilots should be encouraged to pursue their instrument rating once the Private Pilot certificate has been earned.

3. Flight instructors should be truthful and should not minimize the risks involved in flying an aircraft. Presenting the risks involved in specific flight situations, including the risks associated with scud running, should be accompanied by an explanation of risk management concepts.

4. Flight instructors should incorporate hazardous weather avoidance procedures applicable to the VFR-intoIMC scenario into their teaching.

5. Pilots should be taught not to allow the fear of certificate action to outweigh the need to request assistance. Teaching pilots to ask ATC or FSS for a "flight assist" and explaining the probable outcomes of such a request can help alleviate such fears.

6. Aviation psychologists and educators should continue 
research into the various aspects of $\mathrm{ADM}$ and their findings

should be incorporated into pilot training programs. $\bullet>$

Dale R. Wilson is an associate professor in the Industrial \& Engineering Technology department at Central Washington University. He earned a B.A. in Psychology (human performance emphasis) from TWU and an M.S. in Aviation Safety from Central Missouri State University. He holds ATP certification in the United States and Canada as well as FAA-certified flight and ground instructor certificates. He also has Master CFI designation from the National Association of Flight Instructors (NAFI). He serves as an FAA Aviation Safety Counselor for the Spokane Flight Standards District Office.

Teresa A. Sloan is an associate professor in the Industrial \& Engineering Technology department at Central Washington University. She holds an Air Transport Pilot certificate in single engine land (with commercial privileges in airplane single engine sea and multi engine land) and is an instrument flight instructor. She holds a Master's degree in Initial Teaching from Gonzaga University, a Bachelor of Arts degree in Management from The Evergreen State College, and a Bachelor of Science degree in Aerospace Science from Central Washington University. 
Journal of Aviation/Aerospace Education \& Research, Vol. 13, No. 1 [2003], Art. 9

VFR Flight Into IMC

\section{REFERENCES}

Air tour operators in the state of Hawaii: Final Rule, Federal Register 27919 (September 26,1994) (codified at 14 C.F.R. pt. SFAR).

AOPA Air Safety Foundation. (19\%). Safety review, general aviation -weather accidents: An analysis and preventive strategies. Frederick, MD: Author.

AOPA Air Safely Foundation. (1999). Nail report: General aviation accident trends and factors for 1998. Frederick, MD: Author.

AOPA Air Safety Foundation. (2001). Noll report: General aviation accident trends and factors for 2000. Frederick, MD: Author.

ARNAV Systems. (2001, October 2). MFD 5200 frequently asked questions. Retrieved July 2,2002, from http://www.arnav.com/fiM.htm

Bendix/King. (n.d.). KMD 550 \& KM) 850 Multi-function displays. Retrieved July 10, 2002 from http://www.bendixking.com/static/new/new products.html

Bertorelli, P. (n.d.) Declaring an emergency. Retrieved July 16, 2002 from http://www.avweb.com/articles/declare.html

Braukus, M., \& Barnstorff, K. (1999, May 13). Synthetic vision to help pilots. NASA Space Link 99-05-13. Retrieved July 2 , 2002, from http://spacelink.nasa.gov/NASA.News/NASA.News.Releases/Previous.News.Releases/99.News.Relea 05 .News.Releases/99-05-13. Synthetic. Vision.to.Help.Pilots

Civil Aviation Authority of New Zealand. (2002, July 1). Civil Aviation Rules New Zealand (Part 91 general operating and flight rules, subpart D, visual flight rules, 91.301 VFR meteorological minima). Retrieved July 12,2002, from http://www.caa.govt.nz

Civil Aviation Safety Authority of Australia. (2002, April 18). Aeronautical Information Publication Australia (ENR 1.2, Section 2, Visual meteorological conditions). Canberra, Australia: Aeronautical Information Service, Airservices Australia.

Commercial passenger-carrying operations in single-engine aircraft under instrument flight rules: Final rule, Federal Register 28743 (August 6,1997) (codified in 14 C.F.R. pt. 135).

Echo Flight. (2002). Landsat satellite imagery. Retrieved July 10,2002, from http://www.echoflight.coin/GPS NAV/Landsat/landsat.html

Federal Aviation Administration. (n.d.). Safety reports: Weather study index. Retrieved July 10,2002, from http://www.asy.faa.gov/safety_analysis/weather_study/default.htm

Federal Aviation Administration. (2000, September 1). Aviation safety program managers'handbook. Order 8740. ID. Retrieved Jury 19,2002, from http://www.faa.gov/avr/afs/faa/home.html

Federal Aviation Administration. (2002). Private pilot airman knowledge test question bank (June 11,2002 version). Retrieved Jury 10,2002, from http://av-mfo.faa.gov/data/ainnanknowledge/par.txt 
Wilson and Sloan: VFR Flight Into IMC: Reducing the Hazard

Federal Aviation Administration GA Joint Steering Committee. (2001, March 26). Fact sheet: Safer Skies accomplishments, general aviation. Retrieved July 2, 2002, from http://www.faa. eov/apa/FACTSUEET/200 1/fact5mar.htm

Federal Aviation Administration Office of Safe Flight 21 and Surface Technology Assessment. (2002). Safe Flight 21. Retrieved July 12,2002, from http://www.faa.gov/safeflight21/index.htinl

Federal Aviation Administration Research, Engineering and Development (R.E\&D) Advisory Committee. (1997). Subcommittee report of the NAS ATM R\&D panel to R.E\&D advisory committee, March 25, 1997. Washington, DC: Author. Retrieved July 10, 2002, from http://www.fiaa.gov/aar/red/rep-niin/redrep2.htm

14 C.F.R. § 135.205(a). (1991, December 17). Washington, DC: U.S. Government Printing Office. 14

C.F.R. § 91.155(a). (1993, October 5). Washington, DC. U.S. Government Printing Office. 14 C.F.R. §

91.157(b). (2000, March 24). Washington, DC: U.S. Government Printing Office. 14 C.F.R. §

61.101(d). (1997, April 4). Washington, DC: U.S. Government Printing Office.

Goh, J., \& Wiegmann, D. (2001). Visual flight rules (VFR) flight into instrument meteorological conditions (IMC): A review of accident data. In R. Jensen (Ed.), llth International Symposium on Aviation Psychology. Columbus, OH: The Ohio State University.

Goyer, R. (2000, October). ARNAVs FIS system operational. Flying, 127(10), 37.

Hall, J. (1996). Address by Jim Hall, Chairman National Transportation Safety Board for meeting of Alaska Air Carriers Association, Anchorage, Alaska, March 4, 1996. Retrieved July 10, 2002, from http://www.ntsb.gov/speeches/former/hall/ih960304.htm

Khatwa, R., \& Roelen, A. L. C. (1996, April-May). An analysis of controlled-flight-into-terrain (CFTT) accidents of commercial operators, 1988 through 1994 [Electronic version]. Flight Safety Digest, 15, 1-45.

LaBelle, J. (1999). Testimony of James LaBelle, Chief Northwest Field Office, National Transportation Safety Board, before the Transportation Subcommittee, Committee on Appropriations, United States Senate, regarding aviation safety in Alaska, December 14, 1999. Retrieved July 10,2002, from http://www.ntsb.gov/speeches/s991214.htm

Learmount, D. (1995, April 12-18). An invasion of privacy. Flight International, 147, 20-23.

Menzel, R. (1998, April). Analysis shows that CFTT continues to account for the heaviest loss of life worldwide [Electronic version]. ICAO Journal, 55(3), 5-6.

National Research Council. (1995). Aviation weather services: A call for federal leadership and action. Washington, DC: National Academy Press.

National Transportation Safety Board. (1988). Safety study: Commercial emergency medical service helicopter operations (NTSB/SS-88/01). Washington, DC: Author.

National Transportation Safety Board. (1989). Safety report: General aviation accidents involving visual flight rules flight into instrument meteorological conditions (NTSB/SR-89/01). Washington, DC: Author.

National Transportation Safety Board. (1995). Safety study: Aviation safety in Alaska (NTSB/SS-95/03). Washington, DC: Author. 


\section{VFR Flight Into IMC}

Night for day. (19\%, January). Callback, 199, 1.

Night-visual flight rules visibility and distance from clouds minimums: Final rule, Federal Register 24772 (September 29, 1989) (codified in 14 C.F.R. pt. 91).

Nordwall, B. D. (2000, August 21). Terrain warning offered for general aviation aircraft Aviation Week and Space Technology, 753(8), 44-49.

CVHare, D. (1990). Pilots' perception of risks and hazards in general aviation. Aviation, Space, and Environmental Medicine, 61, 599-603.

178 seconds. (n.d.). Take five for safety (TP2228E) [Brochure]. Ottawa, Ontario, Canada: Transport Canada.

Pilot, Flight Instructor, Ground Instructor, and Pilot School Certification Rules: Final Rule, Federal Register 25910 (March 31,1997) (codified in 14 C.F.R. pt. 141).

Ross, H. (1975, June 19). Mist, murk and visual perception. New Scientist, 66(954), 658-660.

Sakrison, D. (2001, July 28). Goodrich, AvroTech, and NASA spotlight SmartDeck technology. Airventure Today, 6. Retrieved July 9,2002, from http://www.airventure.org/200 1/Saturdav28/smartdcck.html

Transport Canada. Canadian Aviation Regulations (CARs), 602.115. (1996a, October 10). Ottawa, Ontario, Canada: Author.

Transport Canada. Canadian Aviation Regulations (CARs), 602.17. (1996b, October 10). Ottawa, Ontario, Canada: Author.

Transport Canada. Canadian Aviation Regulations Standards (CARs Standards), 723.22. (1996c, October 10). Ottawa, Ontario, Canada: Author.

Transportation Safety Board of Canada. (1990a). Report of a safety study on VFR flight into adverse weather (Report No. 90-SP002). Hull, Quebec, Canada: Author.

Transportation Safety Board of Canada. (1990b). Safety study of VFR flight into adverse weather: Staff report. Hull, Quebec, Canada: Author.

Transportation Safety Board of Canada. (19\%). Aviation occurrence report: Controlled flight into terrain, Western Straits Air, de Havilland DH3-3 (Turbine) Otter, C-FEBX, Campbell River 7nm NW, British Columbia, 27 September 1995 (Report No. A95H0012). Hull, Quebec, Canada: Author.

Transportation Safety Board of Canada. (2001). Statistical summary: Aviation occurrences 2000. Hull, Quebec, Canada: Author.

United Kingdom Civil Aviation Authority. (19\%, May 24). Civil Aviation Publication United Kingdom (CAP 393, Section 2, Section V, Rule 26, Flight outside controlled airspace). Retrieved July 12,2002, from http://www.caa.co.uk/ publications/search.asp

United States General Accounting Office. (1993). Aviation safety: FAA can better prepare general aviation pilots for mountain flying risks. Report to the Chairman, Subcommittee on Aviation, Committee on Commerce, Science, and Transportation, U.S. Senate. (Report No. GAO/RCED-94-15). Washington, DC: Author. 
United States General Accounting Office. (1998). Aviation safety: FAA has not fully implemented weather-related recommendations. Report to the Subcommittee on Technology, Committee on Science, House of Representatives. (Report No. GAO/RCED-98-130). Washington, DC: Author.

UPS Aviation Technologies. (2002). MX20 Multi-function display. Retrieved July 10,2002, from http://www.uDsat.com/nix20 gen.shtml\#

Wallace, L. (2001, March). Battling the Big Lie: John King's crusade to change aviation's culture [interview]. Flying, $128(3), 82-84$.

Wichman, H. \& Ball, J. (1983). Locus of control, self-serving biases, and attitudes towards safety in general aviation pilots. Aviation, Space, and Environmental Medicine, 54, 507-510.

Wilson, D. R. (1999, November-December). Darkness increases risks of flight. Human Factors and Aviation Medicine, 46(6), $1-8$.

Wilson, D. R., \& Fallshore, M. (2001). Optimistic and ability biases in pilots' decisions and perceptions of risk regarding VFR flight into IMC. In R. Jensen (Ed.), llth International Symposium on Aviation Psychology. Columbus, OH: The Ohio State University. 


\section{AUTHOR NOTE}

Dale R. Wilson, Associate Professor, Department of Industrial and Engineering Technology, Central Washington University; Teresa A. Sloan, Associate Professor, Department of Industrial and Engineering Technology, Central Washington University.

The authors wish to thank Ken Stege (now at Western Oklahoma State College) for providing assistance for this article. Correspondence concerning this article should be addressed to Dale R. Wilson, Department of Industrial and Engineering Technology, Flight Technology Program, Central Washington University, Washington, 98926-7515. E-mail: wilsond@.cwu.edu 